\title{
TECHNICALLY AND ECONOMICALLY FEASIBLE HYDRO POTENTIAL OF SMALL RIVERS IN SERBIA
}

\author{
by \\ Svetlana Stevovic*, Ph.D., C.E., P.E. \\ FACULTY FOR CONSTRUCTION MANAGEMENT, BELGRADE, SERBIA \\ Review paper \\ DOI: 10.5937/termoteh
}

\begin{abstract}
As a renewable energy source that is environmentally friendly and cost-effective, the hydropower potential of Serbia represents a valuable common good and notable economic force in a development strategy of the country. It is an important component of the country's overall energy balance, both at present and in the future. Seventy-seven percent of the hydropower potential of Serbia is technically and economically usable, based on the present energy situation in the country, the latest technical advances, and economic criteria. Out of this amount, eight percent could be generated in small-scale hydropower plants, with an installed capacity less than $10 \mathrm{MW}$. In order to promote acquisition of Green Certificates, stimulate the Clean Development Mechanism (CDM) projects and facilitate the Certified Emission Reduction (CER) trading, Serbia is shifting its development strategy towards renewable energy sources, particularly small-scale HPPs. The necessary project documentation has been prepared, nearly 1,000 potential locations for small-scale HPPs have been identified, and the legislative framework is being synchronized with a world-accepted practice in this field. This paper presents some technical possibilities for the construction of smallscale HPPs in Serbia. The attention is focused on the specific conditions, statistical parameters, and the legislative framework of the country.
\end{abstract}

Key words: Renewable energy sources, small hydro power plants, Serbia, EU, potential, perspectives.

\section{INTRODUCTION}

Given the geomorphologic and hydrologic conditions of Serbia, it can be said that its total available hydropower potential is significant and that Serbia belongs to the water-rich European countries. However, Serbia has a relatively low percentage (up to $46 \%$ ) of technically and economically utilized hydropower (large dams and small-scale hydropower plants including) [1].

Small-scale hydropower plants with small reservoirs (SSHPPs) are a much better fit for the environment and cause fewer hazardous environmental impacts compared to the medium and large ones. They contribute to the hydrologic balance of natural (non-regulated) flows and siltation prevention, thus prolonging the lifetime of utilization and cost effectiveness of large hydropower plants.

SSHPPs in Serbia are mainly used for power generation, residential and industrial water supply, and irrigation [2].

Generally, they are up to $10 \mathrm{MW}$ in capacity. SSHPPs also are constructed to prevent or reduce erosion, floods and droughts, improve agriculture and support small businesses (timber processing, sawmills, stone crushing and grinding plants, etc.). In addition, they contribute to development of cattle breeding, fish breeding, sports, recreation and tourism, provision of the biological minimum, and prevention of population migration from undeveloped rural areas into densely inhabited industrial zones. 
S. Stevovic: TECHNICALLY AND ECONOMICALLY FEASIBLE HYDRO POTENTIAL OF SMALL RIVERS IN SERBIA TERMOTEHNIKA, vol. 43, no. 1-4, 2017 pp. 79-85

\section{HYDROPOWER POTENTIAL IN SERBIA AND EUROPEAN UNION}

Utilization of hydropower potential in European Union (EU) is about $65 \%$ on average, whereas for comparison, it is only about $1.2 \%$ in Africa. Some European countries have a very high level of hydropower potential utilization: Norway $100 \%$, France and Italy $87 \%$, Spain and Switzerland $86 \%$, Sweden $65 \%$ [3].

Unfortunately, even with a large natural potential, Serbia has a relatively low percentage of technically and economically feasible hydropower. The total hydropower potential of Serbia (divided among the regions [4]), which could be used in SSHPPs with an installed capacity up to 10MW, is shown in Table 1.

According to a most recent study [5], 856 potential locations for SSHPPs have been identified in Serbia. A complete register of SSHPPs locations is available by region, county, watershed, stream, and cadastral maps. Each location is listed with its technical specifications, installed capacity, and annual power generation.

Presently, Serbia has $448,553 \mathrm{~kW}$ of technically feasible small - scale hydropower potential, with an estimated annual power generation of $1,590,445 \mathrm{MWh}$. Seventy percent of the total installed capacity in SSHPPs belongs to small hydropower plants below $2 \mathrm{MW}$ in capacity $(75 \%$ in a range $0-500 \mathrm{~kW} ; 14 \%$ in a range $501-1,000 \mathrm{~kW} ; 6 \%$ in a range $1,001-2,000 \mathrm{~kW}$; and $5 \%$ in a range $2,001-10,000 \mathrm{~kW})$.

\section{SSHPPS IN OPERATION IN SERBIA AND COMPARISON WITH EUROPEAN UNION}

Serbia is characterized by vast hilly and mountainous regions and numerous streams and small rivers that provide favorable conditions for construction of SSHPPs. Nowadays, there are 39 SSHPPs operating in Serbia [6]. They have a total installed capacity of approximately $49 \mathrm{MW}$ and a total annual output of about 212GWh [7].

For comparison, it should be noted that more than 1,500 SSHPPs operate in Austria, more than 5,000 in Germany, whereas in Norway, the annual output of electric power in SSHPPs exceeds 6,000GWh [8].

Construction of a large number of SSHPPs cannot solve the problem of consumers' growing requirements for energy. However, hydropower potential could be used much more efficiently as a low-cost and renewable source of energy, which is always available, thus reducing utilization of non-renewable and ecologically less clean fossil fuels.

\section{OLD HYDROPOWER PLANTS, MILLS AND EXISTING DAMS- RECONSTRUCTION POSSIBILITY}

Construction of SSHPPs immediately after the World War II was neglected in Serbia. The main cause for this was a low price of electric power generated by large hydropower plants. At the same time, oil and natural gas for thermal power plants were also cheap, which made SSHPPs less profitable. Therefore, not only that they were not constructed, but also most of those constructed were shut down. This was partially caused by the lack of legislative support.

Before the World War II, about 30 SSHPPs were constructed in Serbia, with a capacity less than 10MW. In the course of time, global energy situation had changed, oil derivatives grew more expensive and utilization of coal, a non-renewable resource in thermal power plants, increased. All that caused a renewed interest in clean hydropower generated by both large and small facilities [8]. 
Since the World War II, the deserted SSHPPs have become particularly interesting. There are about sixty such structures in Serbia. These structures could become functional again as sawmills, stone grinders, etc. with some additional modifications and installation of adequate equipment.

The extent of civil works significantly impacts the cost of SSHPPs construction, and consequently the price of generated electric power. Therefore, especially in the beginning, SSHPPs should be constructed on locations with previously completed, or at least partially completed, civil works. Such possibilities exist in Serbia. Adaptation of the existing mills and old abandoned SSHPPs, reduces investments per kW of installed capacity due to existence of structures. The hydraulic structures of mills are well preserved and with small reconstruction could be adapted and used for SSHPPs construction. Some of the SSHPPs could be refurbished with low investments, so that they can be utilized again.

There is also a possibility of addition of small turbines to existing dams, most commonly installed in bottom culverts or pipes for the provision of the biological minimum.

\section{EQUIPEMENT AND SAFETY}

The equipment of existing SSHPPs in Serbia is predominantly old, worn out, and overdue for general maintenance. However, these facilities are still in operation with significantly reduced safety. There were fatal accidents due to high voltage (e.g., HPP Krupajsko Vrelo) caused by inadequate insulation of electrical cables between hydropower plants and consumers. Some of those SSHPPs are part of global power system of the country, some generate electricity only locally. Because there are many safety concerns related to old SSHPPs, this opens up new possibilities for investment into equipment maintenance and reconstruction of entire facilities. An exception is equipment installed in newly constructed facilities, after the process of privatization took place in the country. These are the up-to-date turbines, generators, valves, etc. with a safety factor in compliance with criteria set in developed countries. All the equipment for SSHPPs must be imported since there is no single manufacturer in the country.

Newly designed SSHPPs are intended to operate in accordance with all the technical standards and criteria of European Union, with appropriate safety factors for statics, hydraulics, hydrology, sedimentation and erosion [9].

\section{PURPOSE OF SMALL HPP IN SERBIA}

Multipurpose utilization of low-flow hydropower potential is an optimal solution for construction, costefficiency, and operation of SSHPPs:

- Main purpose of SSHPPs is electric power generation. It is usually intended for some local consumers (sawmills, timber industry, stone crushing, grinding plants, etc.).

- Small reservoirs are also used for agricultural irrigation. They are most often constructed in undeveloped, mountainous areas, where water is necessary for agriculture (cultivation and cattle breeding). This has a favorable impact on the growth of undeveloped regions, and at the same time, reduces migrations into heavily populated industrial zones.

- Residential and industrial water supply is another purpose of small reservoirs, impacting local developments and agriculture, subsequently reducing migrations from villages into towns.

- Small reservoirs provide flood control, and therefore, protection of human lives and common goods against uncontrolled water power.

- Such reservoirs contribute to land protection against erosion, prevent siltation in the downstream, larger reservoirs, and thus prolong their lifetime.

- Small reservoirs, and small-scale hydropower plants, provide the biological minimum above low discharges downstream from dams in dry seasons. They improve the hydrologic balance and thus contribute to environmental protection.

- Fish breeding and production are very successful in small ponds and streams created by SSHPPs.

- Small reservoirs contribute to tourism, sports, and recreation. Urban population, running away from polluted cities, increasingly returns to nature, especially small aquatic environments formed by SSHPPs [9]. 


\section{COST, ENERGY EFFICIENCY AND ENVIRONMENTAL EFFECTS OF SSHPPS}

Water power is a renewable source of energy. The water used in hydropower plants remains available to other consumers in various domains of water resources management. SSHPPs have all the advantages in comparison with other facilities for electric power generation. Unlike medium and large power plants, SSHPPs better fit into the environment and create fewer hazardous environmental impacts. Because these structures are of a relatively small size, they have less effect on the surroundings. Sometimes, there is no obstruction by a reservoir at all, which is the case in run-through facilities [10].

The hydropower potential of Serbia is widely dispersed. As a renewable energy source that is environmentally friendly and cost-effective, the hydropower potential of Serbia represents a valuable common good and notable economic force in a development strategy of the country. It is an important component of the country's overall energy balance, both at present and in the future [11].

Utilization of water power represents the most important alternative to energy generated from fossil fuels. It is an inexhaustible source of energy and the cleanest mode of operation from the aspect of environmental protection. At the same time, coal and oil reserves are spared from depletion, with additional savings for an expensive liquid fuel necessary in thermal power plants.

Implementation of SSHPPs in Serbia would provide cost effective electric power. Each kWh of generated water power in SSHPPs represents an energy equivalent of $1.6 \mathrm{~kg}$ to $2.2 \mathrm{~kg}$ of coal (depending on the kind and quality) or approximately $0.25 \mathrm{~kg}$ of heavy oil [12].

One of the major advantages of SSHPPs is a short construction period. This holds particularly for civil works, as the prices of construction materials, manpower and equipment constantly change. A big advantage of the short construction period is fast commencement of operations, quick return of investments, and prompt utilization of lowcost and renewable energy.

An average price of a $\mathrm{kW}$ of installed capacity in SSHPPs, as a rule, is higher than in large hydropower plants. However, if SSHPPs are built as multipurpose structures, investments in them are expected to be lower than in large ones.

Construction of SSHPPs in the consumers' immediate vicinity (to be close to the main distribution network) and with the exclusive purpose to meet the requirements of those consumers, involves significantly lower investments for generation of a kWh of electric power than it would be the case with large hydropower plants, as there are no transmission lines expenses, nor losses of electric power in transmission. Additional advantages of SSHPPs, in comparison with large ones, are low operation and maintenance costs without the need for permanent staff [13].

\section{SUPPORTING MECHANISM OF EUROPEAN UNION AND LEGISLATIVE FRAMEWORK IN SERBIA}

The promotion of renewable energy sources, including SSHPPs, is a high priority of European Union, declared in numerous strategic documents. The most important one is the Document 2001/77/EZ dated September 27,2001 regarding the promotion of renewable energy sources on the internal market of electric energy. The purpose of this document is endorsement of increase of renewable energy sources on the internal market and creation of a unified energy framework. The goal is to reach a renewable energy share of $22 \%$ by 2010 , nearly double the amount from 1997. The attained renewable energy share in 2003 was about $15 \%$, [14].

The Document explicitly states that the promotion of renewable energy sources is a high priority of European Union because it provides security and diversification of energy supplies, as well as protection of the environment and economic cohesion. Since renewable energy sources are still not competitive enough to fossil fuels, unless expenses for environmental protection are included in production costs, it is necessary to introduce a promotion mechanism to compensate (unequal) subventions for conventional energy sources. There are two basic regulatory principles for promoting energy generation from renewable sources:

- Quantitative approach (quota)

- Price approach (feed-in).

The above approaches are being incorporated in the Serbian legislative framework. In addition, it is planned to introduce other promotion mechanisms, such as investment subventions and tax-free financing. It is also important to note that Serbia will soon establish ecological subsidies that are expected to have significant effect on utilization of all renewable resources, especially when these subsidies are based on the actual environmental protection cost. 
Some problems and limitations related to the contribution of renewable energy sources to the global energy system of the country are as follows:

- High start-up cost - additional (incremental) expenses for energy production from renewable energy sources

- Deficiency of some (old) technologies

- $\quad$ Problems with the global energy system management due to relatively high proportion of decentrilized (independent) energy producers (high intermittency).

The optimal solution for any country is always a compromise between various alternatives. One of the basic prerequisites for successful implementation of SSHPPs as renewable energy sources, besides elimination of administrative obstacles, is proper pricing (establishment of electric power tariffs) and duration of electric power selling on the market. These issues are currently being resolved by the Serbian Ministry of Energy [15].

\section{PERSPECTIVES FOR SMALL HPP IN SERBIA}

Given the fact that SSHPPs generate clean, renewable energy with minimum hazardous environmental impacts, that they promote industry development and electrification of remote rural areas far from roads and traffic routes, it is clear why all the countries, both developed and undeveloped ones, try to foster hydropower utilization in SSHPPs by means of various measures.

For example, the Norwegian government, which has almost one hundred percent utilization of its hydropower potential, provides non-refundable financial aid for construction of SSHPPs amounting to $80 \%$ of the total value of the structure. Such a large subvention is of significant economic importance, as it pertains to structures which are usually built outside the main power network as independent energy sources for a small number of consumers [16].

Serbia has favorable topographic and hydrologic conditions for construction of SSHPPs, but not enough attention has been paid to them so far. Nowadays, with a number of already built small reservoirs and the necessity for mass construction of these structures, the possibilities for construction of SSHPPs are quite increased. The following activities are taking place in the domain of SSHPPs construction [4]:

- $\quad$ Reconstruction and refurbishment of the existing SSHPPS

- Automatization of SSHPPs which already operate

- $\quad$ Adaptation of the existing mills into SSHPPs

- Housing of new units with installed capacities up to 10MW within the existing dams and hydropower plants, for additional utilization of the available discharge and hydropower potential

- Construction of new plants as separate structures

In order to begin utilization of the existing hydropower potential in SSHPPs as soon as possible, our country is carrying out standardization of projects and equipment for SSHPPs. Construction of standard civil structures is the first step towards standardization of the required electromechanical equipment, which implies faster and easier installation of automated control systems in SSHPPs without crew [17].

Another avenue is searching for all those abandoned structures and mills that could provide electric power with minimum civil works, which is of great importance for local consumers. All the possibilities for construction and reconstruction of SSHPPs with various consumers are being analyzed.

In stimulating the construction of SSHPPs [18], important factors are the legislative framework and financial reliefs. The required technical documentation for the design, construction and operation of SSHPPs, as well as environmental permitting (fire protection, endangered species, etc.), is simplified compared to structures with larger installed capacities.

The financial and economic support for SSHPPs is provided through:

- Credits and subventions

- Stable market conditions for electric power delivery from SSHPPs

- Tax relief for contractors involved in construction of SSHPPS

- Tax-free importing of equipment and devices 


\section{CONCLUSION}

Construction of a large number of SSHPPs cannot solve the problem of consumers' growing requirements for energy.

However, hydropower potential could be used much more efficiently as a low-cost and renewable source of energy, which is always available, thus reducing consumption of non-renewable and ecologically less clean fossil fuels.

SSHPPs with modern structural solutions are easy to construct, operate, and maintain. With standardized electro-mechanical equipment and well established civil works, they reduce the cost of construction and maintenance and provide rapid return of investments.

Construction of SSHPPs in Serbia depends on large hydropower potential and on manufacturing of electrical, mechanical and hydro mechanical equipment. The existence of such structures alleviates the country's energy crisis, provides stable economic development and the best fit into the environment.

It is very important to continue working on standardization of the design and equipment for SSHPPs.

Also important is to explore various possibilities for co-financing and simplification of the legislative framework pertaining to design, construction, and operation of SSHPPs, as well as their incorporation into the global energy system of the country.

\section{REFERENCES}

[1] S. Stevovic and D. Stefanovic, Energy efficiency of conceptual solutions for utilization of renewable resources as a function of sustained development. Beograd, Serbia. 2009. prepared for and financed by Serbian Ministry of Education, Science and Technological Development.

[2] H. Milosevic, N.A. Geydarov, Y.N. Zakharov and S. Stevovic, "Model of incompressible viscous fluid flow driven by pressure difference in a given channel." International Journal of Heat and Mass Transfer, no. 62, 2013, pp. 242-246. doi: 10.1016/j.ijheatmasstransfer.2013.02.059

[3] S. Stevovic, Cadastre of Small Scale Hydropower Plants of the Republic of Serbia. Belgrade, Yugoslavia: Energoprojekt-Hidroinzenjering. 1991.

[4] S. Stevovic, Z. Milovanovic and A. Milajic, "New methodological approach in techno-economic and environmental optimization of sustainable energy production." Thermal Science, vol. 14, no. 3, 2010, pp. 809-819. doi: $10.2298 /$ tsci100510007s

[5] S. Stevovic, H. Milosevic, I. Stevovic and S. Hadrovic, "Sustainable management of water resources in Prokletije region." Industrija, vol. 42, no. 1, 2014, pp. 47-61. doi: 10.5937/industrija42-4699

[6] S. Stevovic, "Small Scale Hydropower Plants as Renewable Energy Sources in FR Yugoslavia", in Med Power Conference, oct.2002. Athens, Hellas. 2002

[7] S. Stevovic, "Small Hydro Electric Plants as Renewable Energy Source in Serbia and Montenegro", in Eights Education and Training Workshop "Environmental technologies, renewable resources, harmony and ethics for sustainable agriculture, food chain and healthy development. 2004. Available from: www.rcuh.bg.ac.yu/deres, okt.

[8] S. Stevovic, Preliminary report for hydropotential exploitation of Babinopoljska reka. Podgorica: Kronor. 2009.

[9] H. Milosevic, S. Stevovic and D. Petkovic, "Numerical simulation of interaction during the top blow in a steelmaking converter." International Journal of Heat and Mass Transfer, vol. 54, no. 19-20, 2011, pp. 4275-4279. doi: 10.1016/j.ijheatmasstransfer.2011.05.018

[10] S. Stevovic, M. Miloradovic and I. Stevovic, "Management of environmental quality and Kostolac mine areas natural resources usage." Management of Environmental Quality: An International Journal, vol. 25, no. 3, 2014, pp. 285-300. doi: 10.1108/meq-11-2013-0121

[11] G. Češljar and S. Stevović, "Small reservoirs and their sustainable role in fires protection of forest resources." Renewable and Sustainable Energy Reviews, no. 47, 2015, pp. 496-503. doi: 10.1016/j.rser.2015.03.071

[12] S. Stevovic, Z. Milovanovic and M. Stamatovic, "Sustainable model of hydro power development-Drina river case study." Renewable and Sustainable Energy Reviews, no. 50, 2015, pp. 363-371. doi: 10.1016/j.rser.2015.05.016

[13] O. Paish, "Small hydro power: technology and current status." Renewable and Sustainable Energy Reviews, vol. 6, no. 6, 2002, pp. 537-556. doi: 10.1016/s1364-0321(02)00006-0 
[14] J.S. Anagnostopoulos and D.E. Papantonis, "Optimal sizing of a run-of-river small hydropower plant." Energy Conversion and Management, vol. 48, no. 10, 2007, pp. 2663-2670. doi: 10.1016/j.enconman.2007.04.016

[15] T. Bøckman, S. Fleten, E. Juliussen, H.J. Langhammer and I. Revdal, "Investment timing and optimal capacity choice for small hydropower projects." European Journal of Operational Research, vol. 190, no. 1, 2008, pp. 255-267. doi: 10.1016/j.ejor.2007.05.044

[16] S. Mishra, S.K. Singal and D.K. Khatod, "Optimal installation of small hydropower plant-A review." Renewable and Sustainable Energy Reviews, vol. 15, no. 8, 2011, pp. 3862-3869. doi: 10.1016/j.rser.2011.07.008

[17] D.K. Okot, "Review of small hydropower technology." Renewable and Sustainable Energy Reviews, no. 26, 2013, pp. 515-520. doi: 10.1016/j.rser.2013.05.006

[18] S.K. Singal, R.P. Saini and C.S. Raghuvanshi, "Analysis for cost estimation of low head run-of-river small hydropower schemes." Energy for Sustainable Development, vol. 14, no. 2, 2010, pp. 117-126. doi: 10.1016/j.esd.2010.04.001

Paper submitted: July 17, 2016

Paper revised: $\quad$ August 20, 2016

Paper accepted: $\quad$ August 27, 2016
Copyrights ${ }^{\odot} 2017$ Society of Thermal Engineers of Serbia Published by the VINCA Institute of Nuclear Sciences, Belgrade, Serbia This is an open access article distributed under the CC BY-NC-ND 4.0 terms and conditions 